\title{
Theoretical and Experimental Research of The Stability of The Eccentrically Loaded Steel Columns with Variable Cross-Section
}

\author{
Gennady $\operatorname{Trusov}^{1}{ }^{*}$, Vladimir $\operatorname{Ruban}^{2}$ \\ ${ }^{1}$ Poltava National Technical Yuri Kondratyuk University, Ukraine \\ ${ }^{2}$ Poltava National Technical Yuri Kondratyuk University, Ukraine \\ *Corresponding Author E-Mail: Trysov54@Gmail.Com
}

\begin{abstract}
The article deals with the problem of determining the ultimate load for the eccentrically loaded steel columns with variable-cross section.

The purpose of the research work is to offer an evaluation technique and practical calculation of load-bearing ability of the beamcolumns with variable cross-section on the basis of numerical research, which will allow to consider the true form of element deflection curve, the effect of cross-section form, physical nonlinearity of the material, and variety of element boundary conditions. The distinctive characteristic of the suggested method is usage of the discrete models for cross-sectional parts, for the true stress-strain curves of the materials, and for the other input data. The method was tested and the results were compared to known theoretical solutions and national standards. To establish the reliability of the developed method, the experimental study of steel columns with variable cross-section was conducted. The suggested method allows to obtain column curves tables of lowering coefficients for these elements, that can be used in practice of civil engineering, and are convenient with national standards and Eurocode.
\end{abstract}

Keywords: beam-column; eccentrically loaded elements; stability; steel columns; variable cross-section.

\section{Introduction}

The use of elements with variable cross-section allows engineers to reduce metal consumption considerably, and thus, the cost of constructions. Their main advantage is in optimal use of load-carrying ability of the material along element length, leading to the reduction of construction weight in comparison with traditional techniques. Such constructions have proved well in foreign design practice, have been widely recognized, and are considered perspective $[3,8]$.

At the same time domestic standards [4] lack recommendations on designing elements with variable-cross section, which would consider the specific features of their constructive decisions, and the efficient behaviour under loading.

The base eccentrically loaded element model adopted in national standards requires to check the cross-section in the middle of the element (fig. 1), which corresponds to symmetric loading (the initial moment diagram has rectangular shape), and is the most unpleasant state for the eccentrically loaded elements. In the case of unsymmetrical loading, initial moment diagram has triangular shape (fig. 1), and the main cross-section moves towards the maximum moment, which leads to the increasing of the load-bearing ability of the eccentrically loaded element. As a result, in the case of unsymmetrical triangular initial moment diagram and constant cross-section along the element length, the material in the range of minimal moments is used irrationally. That has made the use of the elements with variable cross-section reasonable in the practice of civil engineers.
The efficiency of such elements is caused by the accordance of the element form to the characteristics of the moment diagram along the element length.

While the problem of the load-bearing ability of eccentrically loaded elements with unsymmetrical initial moment diagram is solved in the domestic standards, there are no recommendations on the calculation of the eccentrically loaded elements with variable cross-section.

The effect of changing of cross-section area along element length on load-bearing ability is not taken into account in standards. The calculation and design of such structures is theoretically complex and deficiently investigated task.

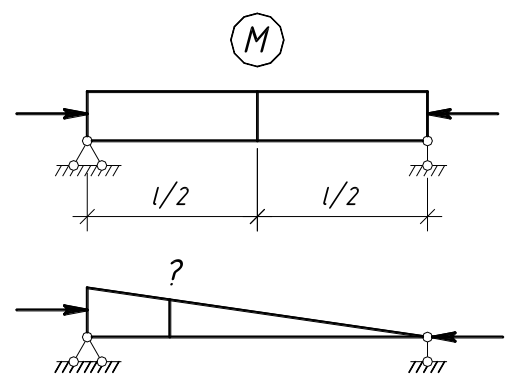

Fig. 1: Initial moment diagrams for symmetrical and unsymmetrical loading cases adopted in national standards 


\section{Main Body}

The analytical review of the works devoted to studying the issues of stability of steel columns with variable cross-section, allows to draw a conclusion that calculation and design of constructions from elements with variable cross-section is a problem which requires further investigation.

The main problems lie in the following:

- Initial moment diagram does not take into account the real shape of the deformed axis of the element, which is important for compression elements with different loading cases.

- Most of the framework members have deformations in both elastic and inelastic range of behaviour, which is connected to the physical nonlinearity of the material.

- Closed-form analytical solution for these elements can be obtained only for a limited number of symmetric cases, since differential equations are too complicated or even impossible to be solved analytically.

Thus, the purpose of the research work was:

1. To offer an evaluation technique and practical calculation of load-bearing ability of the beam-columns with variable crosssection on the basis of numerical research, which will allow to consider the true form of element deflection curve, the effect of cross-section form, physical nonlinearity of the material, and variety of element boundary conditions.

2. To obtain column curves in tabular form (tables of lowering coefficients) for these elements.

In order to achieve these goals, a number of tasks were set: the development of methods and algorithms, the implementation of the algorithms into a computer program, and numerical research of the stability of the eccentrically loaded steel elements with variable cross-section in elastic-plastic state, taking into account the true behavior of such elements.

The concept was based on the following condititons and assumptions:

1. The curvature of the deflected shape of the element is equal to:

$\rho \approx v^{\prime \prime}$,

where - element's deflected shape curvature; $v^{\prime \prime}-$ the displacement of the point towards the axis.

2. The distribution of the axial deformations in cross-section is corresponding to the law:

$\varepsilon_{i}=\varepsilon_{0}+\rho \cdot y_{0 i}$,

where ${ }_{0}$-relative axial deformation in the cross-section's centre of mass; ${ }_{i}$ - the same at certain point of the cross-section; $y_{0 i}$ distance from the centre of mass of the cross-section to the point. 3. The connection between normal stresses and relative deformations is established by the function (in a tabular form):

$$
=f()
$$

4. Pure bending is sustained on the ascending branch of the loaddeflection curve.

The task is to determine element equilibrium in elastic and inelastic regions for any adjusted load $N$. To solve the problem, the numerical integration of the nonlinear differential equation of column buckling is performed.

In general case, the differential equation of beam-column is

$E I(v, z) \cdot v^{\prime \prime}(z)+N \cdot v(z)=-M(z)$

where $E I(v, z)$ - bending stiffness of the element at some crosssection $z ; N$ - axial force; $M(z)$ - bending moment at crosssection $z$.

The equation (4) is solved using the numerical shooting method. The main idea lies in the reducing of the initial boundary value problem to solving several Cauchy problems for a given differential equation.

The element is divided into adjusted number of sections (fig. 2). At the ends (junction points) of each section the cross-section's deflection and angular rotation are calculated. For particular load the task is solved by iteration method. Repeated calculations are carried out until the desired boundary values at the ends of the element are found.

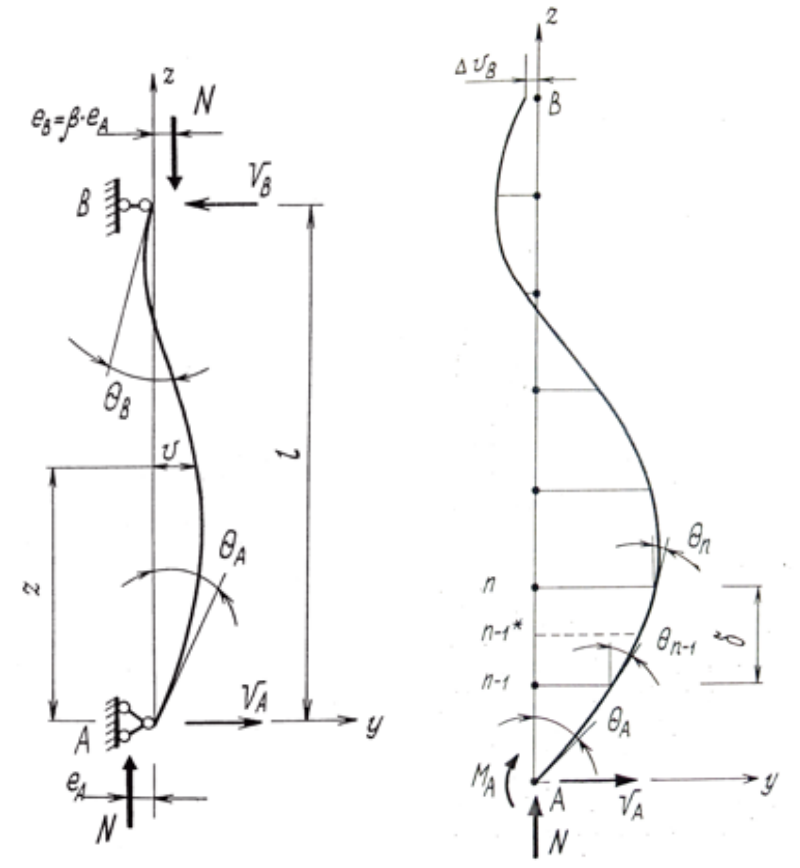

Fig. 2: The element's deflected curve

The distinctive characteristic of the suggested method is usage of the discrete models for cross-sectional parts, for the true stressstrain curves of the materials, and for the other input data.

The cross-section of any arbitrary shape is divided into adjusted number of elementary areas (fig. 3 ).

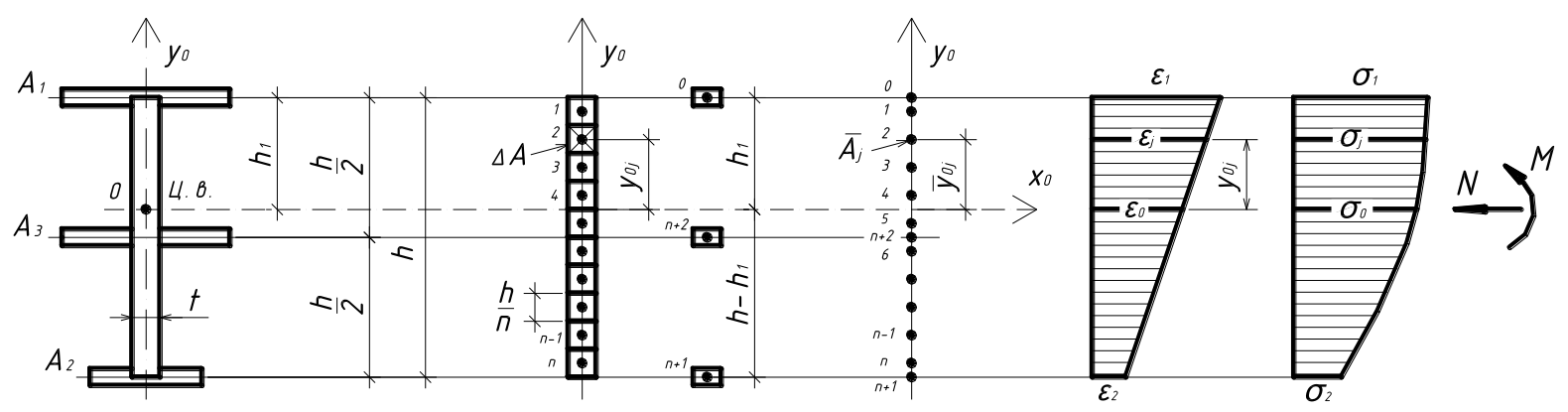

Fig. 3: The discrete model of cross-section 
To determine stresses and strains in the cross-section of the element under specified loading conditions and take into account the true stress-strain diagram of the material, additional algorithms have been developed. Mathematical base of the algorithms can be found in the works $[9,10]$.

The main cross-section equation determines the equilibrium of the external and internal forces.

Applying the method of steepest descent, the values of strain and curvature are determined with adjusted accuracy at every point of the cross-section for any combination of the external forces.

To improve computation efficiency, systemize and extend the results of research to various types of steel and cross-sections, all calculation constants and variables are reduced to convenient dimensionless parameters.

Then the algorithms have been implemented in the programming environment. The program allows to calculate limiting loads for the eccentrically loaded steel elements with constant and variable cross-sections. The main principle lies in constructing the loaddeflection diagrams.

To verify the developed method, a comparison of the calculations performed by the developed program with the results of admitted theoretical studies (fig. 4) and national standards (fig. 5) had been performed. The correspondence was good.

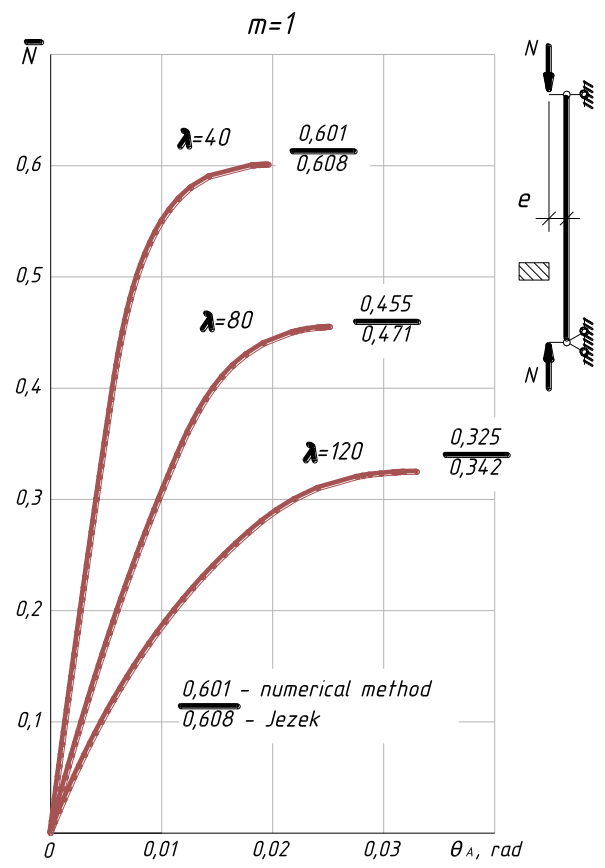

Fig. 4: Load-deflection curves for the eccentrically loaded steel columns with constant rectangular cross-section. Comparison of the data obtained by numerical method to Ježek's study [7].

A mathematical model describing the change of the cross-section along the element length has been developed. The geometric similarity of the cross-sections is considered, and additional input parameters are used, the main of which is the coefficient of the cross-section change along the element length.

The corresponding expressions for the basic geometric characteristics of the section are determined taking into account principles of theory of similarity. In the iterative process of finding the shape of the deformed axis of the element, the geometrical characteristics for each cross-section are calculated, program forms an array of areas and their coordinates.

To establish the reliability of the developed method, the experimental study of steel columns with variable cross-section was conducted. The task was to determine the ultimate loads of steel columns with unsymmetrical loading case and study the columns behavior in the region of the ascending branch of the loaddeflection curve.
The study was conducted on six samples (fig. 6) of the welded I-beams with cross-section height of $150 \mathrm{~mm}$ and a variable flanges width.

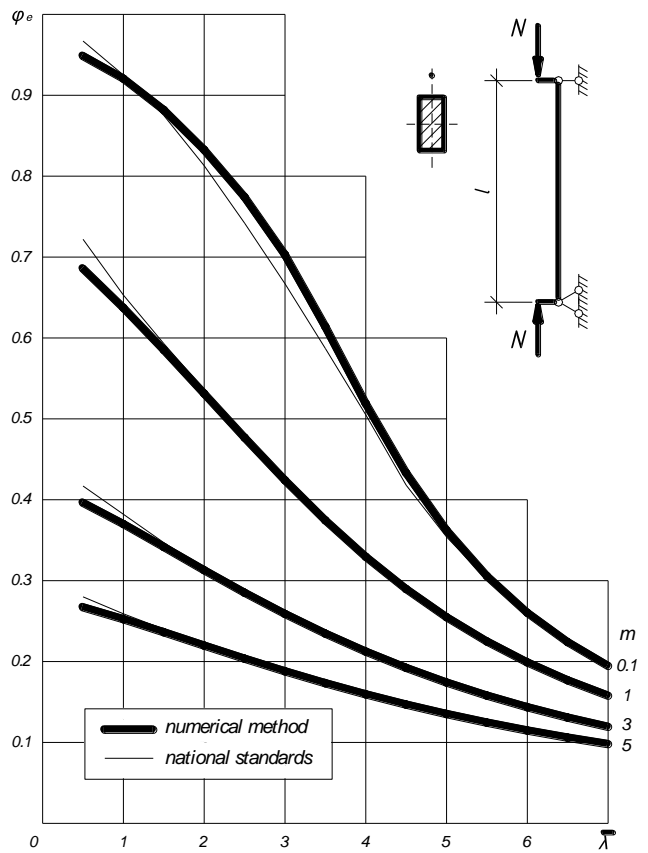

Fig. 5: Column curves for the eccentrically loaded steel columns with constant rectangular cross-section. Comparison of the data obtained by numerical method to the national standards recommendations [4]

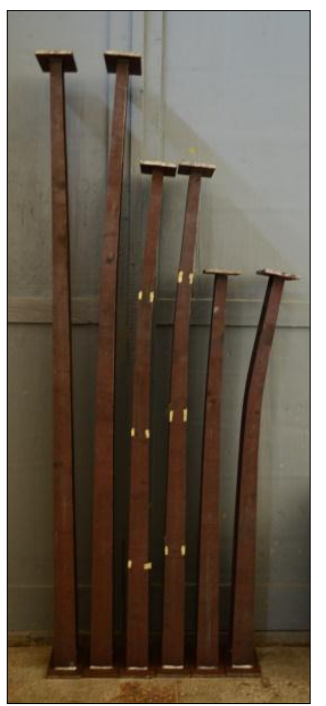

Fig. 6: The samples after being tested

Flexibility in the plane of the least stiffness of the element's crosssection was within the range of $80 \ldots 120$, which practically covers the range of the most commonly used flexibilities of steel structures elements.

Experimental data were compared to the results of theoretical studies. The figures 8 and 9 show load-deflection diagrams and the deflections of the axis.

Experimental and theoretical curves are presented in dimensionless parameters by the results of computer processing of the experiment data.

The comparison of the results of the values of the ultimate loads for various elements showed that the experimental and theoretical data have a good correspondence with each other-the difference is $10-15 \%$.

Thus, the developed research technique describes accurately enough the actual work of the eccentrically loaded steel columns with the variable cross-section and can be used for design and calculations. 


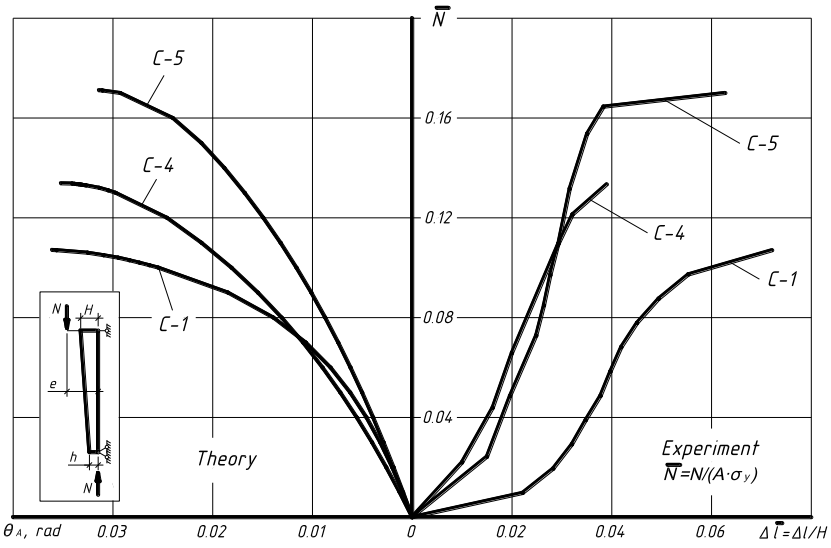

Fig. 7: Load-deflection diagrams. Load to rotation angle (theoretical) and load to changes in distance between supports (experimental).

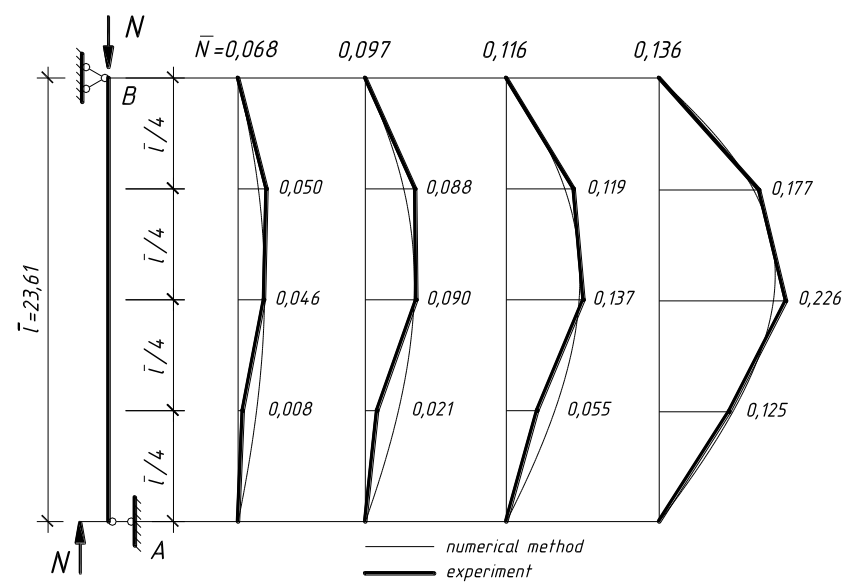

Fig. 8: The deflections of axis of the element

Numerical research (fig. 9) of load-bearing ability of the eccentrically loaded steel columns with variable cross-section was carried out. The column curves and tables of lowering coefficients were obtained (fig. 10, 11). The transition to other forms of crosssections can be performed according to the national standards [4] or Eurocode [5].

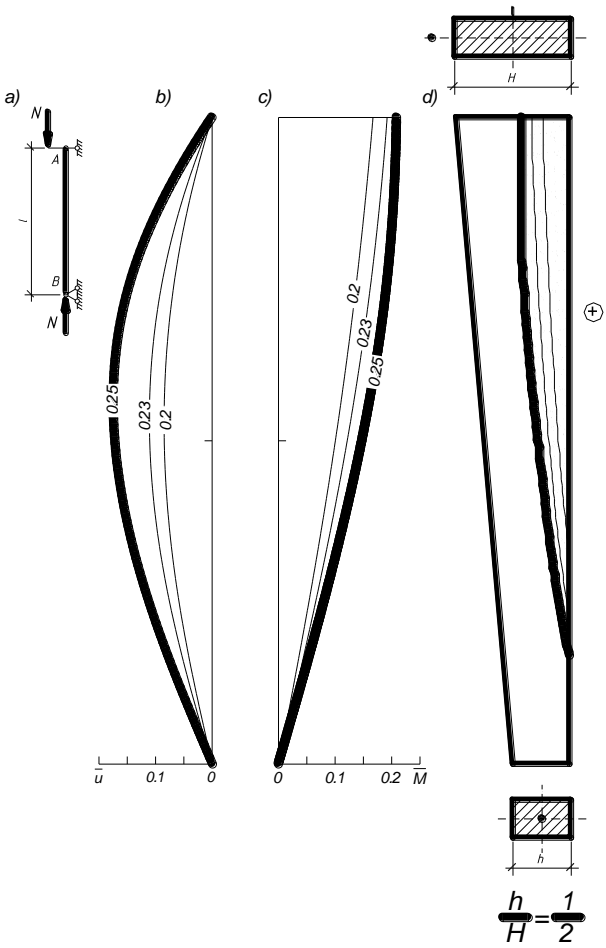

Fig. 9: Column stress-strain state during the loading $\left(\lambda=2.0 ; m_{A}=5.0\right)$; a) loading scheme; b) lateral deformations of the deflected axis; c) moment diagram; d) inelastic deformations zones.

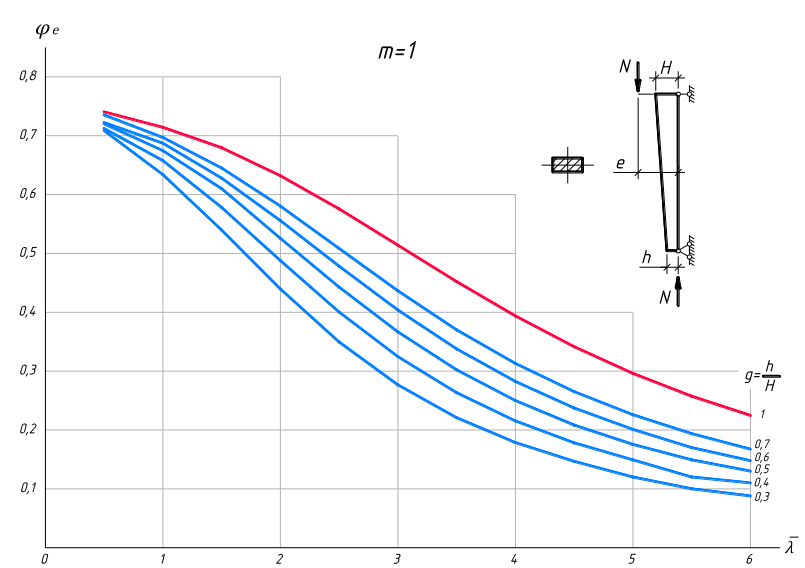

Fig. 10: Column curves for the eccentrically loaded steel columns with variable rectangular cross-section

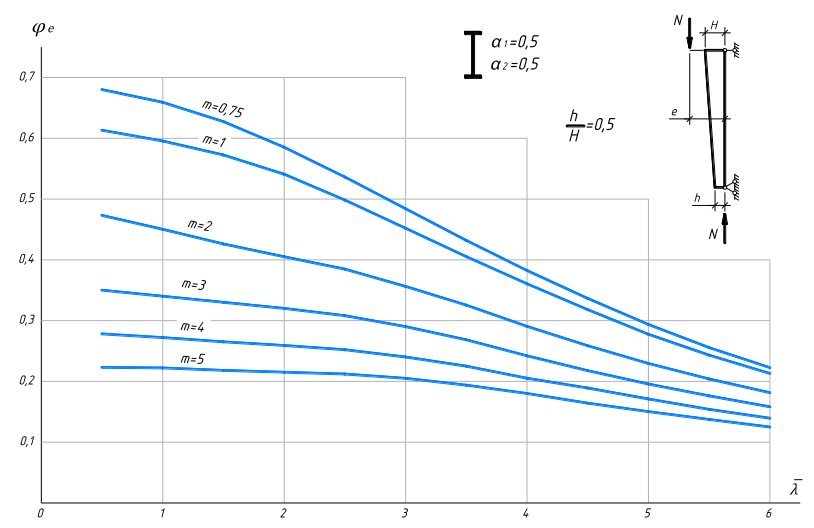

Fig. 11: Column curves for the eccentrically loaded steel columns with variable I-shape cross-section. The ratio of the end webs heights is 0.5 .

\section{Conclusion}

The following conclusions were reached on the basis of the numerical and experimental research:

1. The problem of determining the load-bearing ability of the eccentrically loaded steel columns with variable cross-section could be solved only by numerical research, which would consider the true behavior of such elements.

2. The suggested method allows to obtain column curves and tables of lowering coefficients for the eccentrically loaded steel columns with variable cross-section. These data could be used in practice of civil engineers, by the same design and calculation methods that are presented in national standards [4] or Eurocode [5].

3. The approach is applicable for any cross-section form and takes into account the true form of element deflection curve, physical nonlinearity of the material, and variety of element boundary conditions.

4. The distinctive characteristic of the suggested method is usage of the discrete models for cross-sectional parts, for the true stressstrain curves of the materials, and for the other input data.

5. The method was tested and the results were compared to the known theoretical solutions and national standards. To establish the reliability of the developed method, the experimental study of steel columns with variable cross-section was conducted.

6 . It is expected that the implementation of the suggested methodology will allow civil engineers to decrease steel elements metal consumption, and thus, to reduce the cost of structures.

\section{References}

[1] Belskiy GE, "The basics of the unification of inelastic calculation of steel structures" [Osnovy unifikacii raschetov metallicheskih 
konstrukciy za predelom uprugosti], Construction Mechanics and the calculation of structures, No. 3, (1985), pp. 12-15. [in Russian]

[2] Belskiy GE, "Stability of compressed metal rods" [Ustoichivost szhatyh sterzhney], Izvestiya VUZov, No. 11, (1985), pp. 11-24. [in Russian]

[3] Bilyk SI, "Rational steel I-beams with variable height of the web" [Ratsionalni stalevi dvotavrovi balki zi zminnou vysotou stinki], Resourse econmical materials, structures, and buildings: scientific works compilation, Vol. 17, (2008), Ministry of Education and Science of Ukraine, NUVGP, Rivne, pp. 73-78. [in Ukrainian]

[4] DВN В.2.6-198:2015, Steel Structures, Design Standards [ДБН В.2.6-198:2014. Сталеві конструкції. Норми проектування]. [in Ukrainian]

[5] EN 1993-1-1:2005 Eurocode 3: Design of steel structures - Part 1-1: General rules and rules for buildings.

[6] Galambos TV, Surovek AE, Structural Stability of Steel: Concepts and Applications for Structural Engineers, John Wiley \& Sons Ltd., (2008), $381 \mathrm{p}$.

[7] Ježek K, Die Festigkeit von Druckstäben aus Stahl, (1937), Verlag von Julius Springer, Wien, 252 s. [in German]

[8] Katushin VV, Building with steel framework elements with variable cross-section (calculation, desgin, building) [Zdaniya s karkasami iz stalnyh ram peremennogo secheniya (raschet, proektirovanie, stroitelstvo)], Stroyizdat, (2005), Moscow, 656 p. [in Russian]

[9] Kolomiets VP, The method of determination of stresses and deformations in the cross-section of the beam under complex loading, taking into account real stres-strain diagram $(\sigma-\varepsilon)$ [Metod opredeleniya napriazheniy i deformatsiy $\mathrm{v}$ sechenii balki pri slozhnom nagruzhenii s uchetom deistvitelnoi diagrammy $(\sigma-\varepsilon)]$, Izvestiya VUZov, Aviation production, No. 1, (1966), pp. 63-72. [in Russian]

[10] Santathadaporu S, Chen WF, Tangent Stiffness Method for Biaxial bending, Proc. ASCE, J. Structural Div., (1972), Vol. 98, No. 1, pp. 153-163. 